\title{
Laparoscopic Colectomy: The View from the United Kingdom
}

\author{
Nigel Mark Bagnall • Omar Faiz
}

Received: 28 November 2012 / Accepted: 27 March 2013 /Published online: 18 April 2013

(C) 2013 The Society for Surgery of the Alimentary Tract

\section{Dear Sir}

We would like to thank Fox and colleagues for their study of laparoscopic colectomy outcomes. ${ }^{1}$ Firstly, their study highlights the widespread use of laparoscopic colorectal surgery in the US. More than half of all colon cancer operations in their study cohort were approached using minimal access surgery. A similar trend is also being observed in the UK.

Secondly, now that laparoscopic surgery is the preferred approach for colon cancer surgery, the benefits reported in research trials must be demonstrable in mainstream practice. Of note, reductions in postoperative morbidity and length of hospital stay were observed in the study. The authors comment that no significant correlation was identified with respect to mortality. However, mortality was in fact lower amongst laparoscopic cases ( 0.7 versus $1.2 \%, P=0.05)$. Our group recently reported an analysis of the administrative dataset for England, and found that patients undergoing laparoscopic colorectal resection had significantly lower in-hospital mortality $(1.7$ versus $3.4 \%, P<0.001)$ and less morbidity at 30 days (odds ratio $0.79, P<0.001$ ), a difference which was sustained at 365 days (odds ratio 0.81 , $P<0.001)$ compared to the open approach following casemix adjustment. ${ }^{2}$ As such, real-life practise as evaluated from administrative databases suggest that outcome amongst patients selected for laparoscopic surgery is superior to those undergoing conventional surgery.

Third, Fox and colleagues identified a higher rate of intraoperative complications amongst patients treated using laparoscopy. This may be concerning if due to accidental

N. M. Bagnall $(\bowtie) \cdot$ O. Faiz Imperial College London, London, England, UK

e-mail: nbagnall@imperial.ac.uk injury to viscera. However, intraoperative bleeding in laparoscopic cases may be coded as 'haemorrhage', as it is cited as a reason for conversion to open surgery. Similar or higher volume blood loss in open surgery may not be commented upon and therefore not coded.

Finally, there are long-term advantages of minimally invasive procedures over open surgery. We have demonstrated in a study using national administrative data that patients who undergo laparoscopic surgery have lower rates of admission or surgery for adhesions (odds ratio 0.80 , $P<0.001))^{3}$ This is not only of clinical significance, but importantly must be factored into healthcare cost analyses, together with savings from reductions in length of stay and perioperative complications. We applaud Fox and colleagues for their study, which adds further evidence for the wider adoption and equity of access of laparoscopic surgery for patients with colorectal cancer.

NM Bagnall, O Faiz

\section{References}

1. Fox JP, Desai MM, Krumholz HM, Gross CP. Hospital-level outcomes associated with laparoscopic colectomy for cancer in the minimally invasive era. J Gastrointest Surg. 2012 Nov;16(11):2112-9.

2. Mamidanna R, Burns EM, Bottle A, Aylin P, Stonell C, Hanna GB, Faiz O. Reduced risk of medical morbidity and mortality in patients selected for laparoscopic colorectal resection in England: a population-based study. Arch Surg. 2012 Mar;147(3):219-27. Epub 2011 Nov 21.

3. Burns EM, Currie A, Bottle A, Aylin P, Darzi A, Faiz O. Minimal-access colorectal surgery is associated with fewer adhesion-related admissions than open surgery. Br J Surg. 2012 Nov 12. doi: 10.1002/bjs.8964. [Epub ahead of print] 